\begin{tabular}{|c|c|c|c|c|}
\hline Det. No, & $\begin{array}{c}\text { Grams } \\
\text { cracker dust. }\end{array}$ & $\begin{array}{c}\text { Cc. } \mathrm{KIO}_{3} \text { solution } \\
\text { (I.0 mg. I per Io cc.) }\end{array}$ & $\underset{\text { present. I }}{\text { Mgen }}$ & $\begin{array}{l}\text { Mg. I } \\
\text { found. }\end{array}$ \\
\hline I. . & $\ldots 3$ & 10 & 1.0 & 0.91 \\
\hline $2 \ldots$ & $\ldots \ldots 2$ & I 2 & I. 2 & I. 2 \\
\hline $3 \ldots$ & $\ldots \mathbf{I}$ & 8 & 0.8 & 0.82 \\
\hline $4 \cdots$ & $\ldots \mathbf{I}$ & Io & 1.0 & I. 04 \\
\hline $5 \ldots$ & $\ldots \ldots I$ & 12 & 1.2 & 1.23 \\
\hline
\end{tabular}

The observation reported by Riggs probably resulted from his failure to remove completely the residual iodine from the acid aqueous layer before applying his reduction process. There is a distribution of the liberated iodine between the carbon tetrachloride and the acidified aqueous layer and, since at extreme dilution the constancy of distribution coefficients disappears and immiscible solvents extract successively smaller relative amounts of given substances, it follows that the complete removal of the last portions of iodine from the aqueous layer is a matter of considerable difficulty. This fact therefore plays a very important part in the modified method as proposed by Riggs since any dissolved iodine, not removed before the reduction process, leads to a positive error. In the Baumann method, however, the loss of iodine due to its solubility in the aqueous layer plays no appreciable part, since the standards used for estimating the iodine are prepared under conditions essentially identical with those under which the solution of the iodine of the sample is prepared.

[From the Huli Phystological laboratory, Untversity of Chicago.]

\title{
METHODS FOR THE QUANTITATIVE CHEMICAL ANALYSIS OF ANI- MAL TISSUES. I. GENERAL PRINCIPLES.
}

By W. Kock.

Received October 12, 1909.

General Principles. - The study of the chemical transformations of the body as a whole has of recent years received a great impetus by the careful revision of methods of urine analysis by Folin. ${ }^{1}$ Such methods permit, however, of only tentative conclusions as to the processes going on in the individual tissues, and the study of the tissues themselves will become sooner or later a necessity. The time appears particularly favorable for a review of what has been done so far and a consideration of just how much can be accomplished with our present knowledge.

A review of the various attempts at the study of tissues by quantitative chemical methods reveals an unusual amount of misdirected effort. Thus on the one hand we have the physiologist, in an attempt to solve his problems making use of chemical methods of doubtful accuracy; on the other hand, the chemist supplying the physiologist with estimations of admirable accuracy as far as chemical technique is concerned, but

1 Am. J. Physiol., 13, 45 (1905). 
representing only the crudest approximation to the data really needed. As an example of the first I need only mention the vast number of fat estimations that have been made by totally inadequate methods and of the second, the common practice of estimating total nitrogen with a considerable degree of accuracy and then calculating from this the protein, on the incorrect assumption that there are no other nitrogen compounds present. In the following pages the attempt will be made to first enumerate the general principles on which chemical methods must rest in order to ensure the accuracy required by the chemist; in the second place the manner in which these methods need to be applied in order to yield results of value to the physiologist. It is the hope to thus supply the physiologist, who wishes to make use of chemical methods with a guide, and to inspire the chemist with more confidence in the possibility of solving physiological problems by chemical methods. Before going on to outline these principles it may be well to review briefly the object for which we are striving, when we make use of chemical methods in the study of tissues.

We have come of late years to regard the living tissues not as aggregates of so-called living molecules, but as a substratum in which a series of correlated chemical reactions take place. The greatest difficulty which confronts us when we attempt to study these reactions on the basis of our knowledge derived from such studies in physical chemistry is due to their complexity, arising from the fact that a number of them are going on at the same time, and if we attempt to study one separately we destroy the correlation. Another disturbing factor, but one no doubt which makes just this complexity possible, is the presence of colloidal particles which have a tendency to form membranes and thus isolate different chemical activities in different parts of the cell. In other words we may consider the chemical activities of the cell as going on in watery solution, and assign to the colloids the function of helping in the control of these reactions, by the formation of semipermeable membranes. The wellknown function of these larger aggregates in anatomical differentiation on the development of specific cell structure is here extended to a differentiation of chemical activities.

These colloidal particles may be considered to be suspended in a more or less watery medium containing inorganic salts and a number of simpler organic combinations among which we find such substances as: Urea, representing end products of metabolism; creatine and taurine, representing intermediary products of cell activity; substances resembling the proteinic acids about to become involved in chemical transformation, and glycerophosphates or substances capable of being built up into complex colloidal molecules. Among these the chemical activities of the cell take place. 
This conception is quite different from the one still accepted in a good many quarters in regard to living matter and substitutes a dynamic basis, more in harmony with chemical principles for the more or less structural or architectural ideas of living or giant molecules (Pflüger) which have come to us from the morphologist. At a later stage I will have occasion to give some figures which indicate that whenever the chemical activities of the cell are greatest, the conditions are such that these reactions can go on in watery solution and involve comparatively small, soluble molecules.

In considering the very complex mixture of substances found in the living cell, with a view of devising methods of quantitative analysis, a number of difficulties present themselves. The foremost objection, the impossibility of studying living matter after it is, dead, is largely disposed of by the considerations of the nature of living matter, as stated above. The precautions which must be taken to avoid post-mortem changes will be discussed more in detail later. Another objection which suggests itself, particularly to the chemist, is the fact that with the exception of a few simple substances like urea or creatine we are really not dealing with definite chemical individuals. Numerous attempts have been made to isolate definite compounds and some authors will refer to proteins as pure, because they are crystalline, but it is extremely doubtful if pure proteins have ever been isolated. Even in the case of lecithins where conditions are simpler, due to the fact that we have a complex molecule built up of a maximum of five cleavage products instead of twenty or more, it is very doubtful if a really pure lecithin has ever been made. Even the simplest conceivable compound built up of choline, glycerophosphoric acid, stearic, and oleic acids could give the possibility of six isomers, four of which, according to Willstätter, very probably exist.

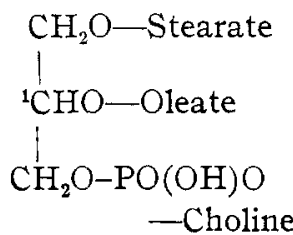

2 Isomers.

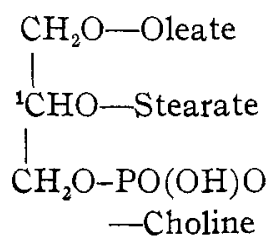

2 Isomers.

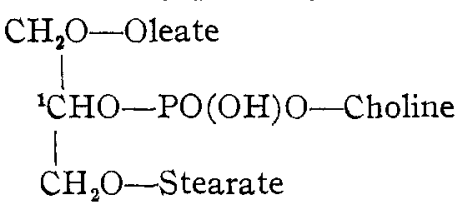

2 Isomers. Probably do not exist.

If we consider, however, the physiological side of the question we can provisionally divide the constituents of the cell into a number of groups which correspond somewhat to chemical groups also and which may be arranged under the following general headings:

(I) Lipoids: Phosphatides, cerebrins, cholesterol, etc.

(2) Extractives: Organic water-soluble compounds not colloidal in nature, e. g., creatine, taurine, hypoxanthine, etc.

${ }^{2}$ Willstätter, R., and Lüdecke, K., Ber., 37, 3753 (1904). 
(3) Inorganic constituents: Represented by ash.

(4) Proteins: Nucleoproteins, phosphoproteins, simple proteins, albuminoids.

(5) Fats: Neutral fats.

(6) Carbohydrates: Glycogen.

The well-known methods for the estimation of these various groups will be discussed in detail later. As a preliminary statement, however, I may say that only very few of them are at all satisfactory. The above groups may be considered as proximate food constituents of the cell and permit of studies as to the state of nutrition. This is especially true of the fats and glycogen, which although they do not belong to the class of colloidal substances referred to previously but are present rather as large masses (fat droplets, glycogen granules), can under proper conditions be very rapidly drawn into the chemical activities of the cell.

Besides studying in general the state of nutrition of the tissue by the proportion of the above groups it is of interest to follow the chemical reactions which are going on. One method of accomplishing this will be the quantitative study of the intermediary and end products of metabolism as found among the water-soluble extractives themselves. Two difficulties present themselves, first our lack of knowledge of the chemistry of the intermediary products and second, the fact that the end products of the reaction like urea, sulphates, and carbon dioxide are eliminated from the cell so rapidly that the amounts present at any one time are not a very good indication of the rate at which they are formed. Such studies as those of Hill ${ }^{1}$ on the measurement of the increase in carbon dioxide content of the blood after it leaves a certain tissue would be valuable but can only find a limited application and can hardly be applied for the estimation of urea or sulphate.

Until we know more of the building stones which go to make up the complex molecules of the cell and of these intermediary metabolic products it is of interest to study the variation in the different elements, nitrogen, phosphorus, sulphur. This would naturally appeal to the chemist as giving him something definite and capable of the application of accurate chemical methods. As a result there are on record a vast number of analyses of total nitrogen, phosphorus, and sulphur in different tissues, made with every regard to accuracy. Unfortunately, however, the chemist has disregarded the fact that such figures are practically useless to the physiologist when he is, for instance, planning a feeding experiment. Thus it is possible to feed exactly the same amount of nitrogen to two animals in the form of different foods and to obtain widely different results in the growth, on account of a difference in the distribution of the nitrogen between protein and extractives in the two foods, or

${ }^{1}$ Hill, L., J. Physiol., 18, 334 (1895). 
again two tissues may have very nearly the same per cent. of total phosphorus in spite of the fact that the distribution of the phosphorus among its various derivatives is quite different, as the following table will illustrate:

\begin{tabular}{|c|c|c|c|c|}
\hline \multicolumn{5}{|c|}{$\begin{array}{c}\text { Distribution OF PHOSPHORUS. } \\
\text { Corpus callosum. }\end{array}$} \\
\hline & $\begin{array}{l}\text { In per cent. } \\
\text { of dry tissue. }\end{array}$ & $\begin{array}{l}\text { In per cent. } \\
\text { of total. }\end{array}$ & $\begin{array}{l}\text { In per cent. } \\
\text { of dry tisstie. }\end{array}$ & $\begin{array}{l}\text { In per cent. } \\
\text { of total. }\end{array}$ \\
\hline Total phosphorus. & I. 5 I & $\cdots$ & 1.45 & $\ldots$ \\
\hline Protein phosphorus. & 0.08 & 5.0 & 0.07 & 5.0 \\
\hline Lipoid phosphorus. . . . . . . & I. $2 I$ & 80.0 & 0.92 & 63.0 \\
\hline Extractive phosphorus..... & 0.22 & 15.0 & 0.46 & 32.0 \\
\hline & I. $5 \mathrm{I}$ & 100.0 & I. 45 & IOO.o \\
\hline
\end{tabular}

The study of the distribution of the three elements-nitrogen, phosphorus and sulphur-is of special interest as they are involved in rather different phases of cell activity. Thus: Nitrogen enters the body and leaves it without changing its state of oxidation. Its distribution between protein and extractives permits conclusions with regard to the metabolism of the proteins. Phosphorus also enters the body and leaves it in the same state of oxidation, but whereas nitrogen is present in combination with hydrogen as ammonia or its derivatives, phosphorus is present in combination with oxygen as phosphoric acid or its derivatives. The study of its distribution permits us to draw conclusions as to the most complex constituents of the cell, the nucleins, and the lecithins (see Groups I and 4). Sulphur differs from the two above named in that it enters the body in the reduced state as cystine and leaves it in an oxidized form, mainly as sulphates. The study of the distribution of its various derivatives forms therefore a means of investigation of reactions of oxidation in the tissues, of which it becomes an index.

The nature of the different compounds of nitrogen, phosphorus, and sulphur as found in the different groups and their relation to one another will be discussed more in detail later. In general those found among the lipoids and proteins may be classed as colloidal and have more of a structural function while those found among the extractives are watersoluble and play a rôle in the more purely chemical transformations of the cell.

So far we have considered the chemist's side of the problem; of what use will the data collected by these methods be to the physiologist. If we confine ourselves merely to the collection of tables of relative composition of different tissues the results may be of value to the dietitian, but will not solve many fundamental physiological problems. We must study the same tissue in different physiological conditions and thus by comparing the results obtained under different conditions we can gain 
some knowledge as to what is going on. The three main conditions under which tissues undergo sufficient change to be capable of detection by chemical means, are in order of importance ( 1 ) the period of growth or development, (2) conditions of pathological change, and (3) conditions of starvation. The variations undergone as a result of physiological activity are as a rule not sufficient to be capable of detection. The formation of lactic acid by muscle and the simultaneous disappearance of glycogen during muscular activity is one of the few exceptions. Even starvation does not affect the active protoplasm of the cell but only its fat and sugar content. As the result of pathological condition, however, profound modifications of the protoplasm may take place and the results thus obtained give us a clearer insight into the nature of the chemical changes in the cell. The difficulty with pathological conditions lies in the fact that very often they are not under experimental control, a fact which makes the interpretation of the results difficult. The most favorable material then on which to study the chemical transformation of the cell is a growing or developing tissue. As a matter of fact the foundations for pathological changes occurring later are very often laid during this early development of a tissue. It is at this stage also that it will be easiest to produce experimental variations. The only difficulty comes

Proximate Constituents in Per cent. of Total Solids.

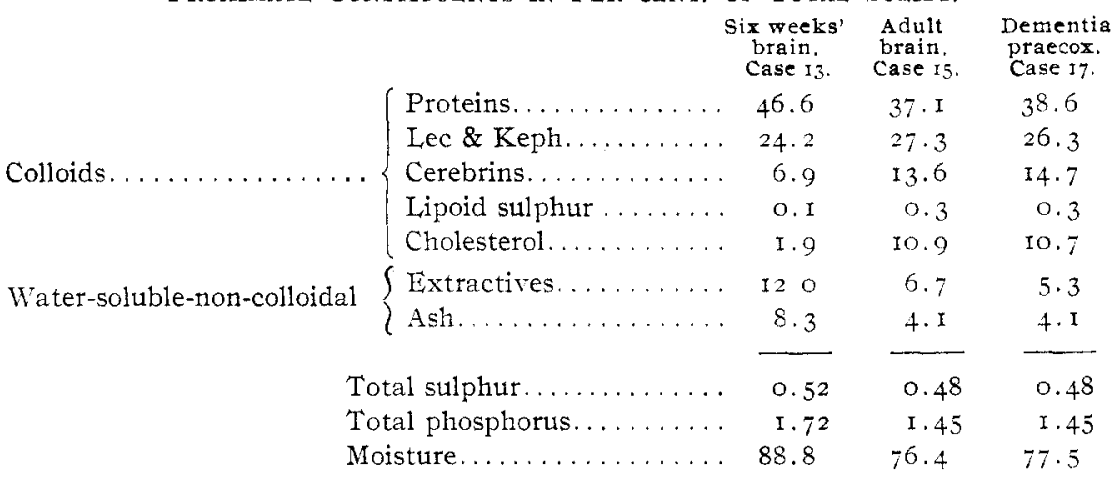

Sulphur in Diferent Groups in Per cent. of Total Sulphur.

\begin{tabular}{|c|c|c|c|c|}
\hline Colloids & $\begin{array}{l}\text { Protein sulphur. . . . } \\
\text { Lipoid sulphur. . . . }\end{array}$ & $\begin{array}{r}62.0 \\
6.0\end{array}$ & $\begin{array}{l}66.0 \\
22.0\end{array}$ & $\begin{array}{l}70.0 \\
22.0\end{array}$ \\
\hline Water-soluble-non-colloidal & $\begin{array}{l}\text { Partially oxidized: pro- } \\
\text { teinic acids........... } \\
\text { Oxidized: sulphates...... }\end{array}$ & $\begin{array}{r}26.0 \\
6.0\end{array}$ & $\begin{array}{l}7.0 \\
5.0\end{array}$ & $\begin{array}{l}4.0 \\
4.0\end{array}$ \\
\hline
\end{tabular}

Phosphorus in Different Groups in Per cent. of Total Phosphorus.

\begin{tabular}{|c|c|c|c|c|}
\hline Colloids & Protein phosphorus.... & 5.0 & 5.0 & 5.0 \\
\hline Water-soluble-non-colloidal & $\begin{array}{l}\text { Lipoid phosphorus....... } \\
\text { Inorganic and in organic }\end{array}$ & 54.0 & 72.0 & 72.0 \\
\hline & combination......... & 41.0 & 23.0 & \\
\hline
\end{tabular}


from the fact that any unfavorable condition of a tissue during growth is apt to lead to morphological change. It will be of interest to study, however, to what extent the chemical activities of the cell can be modified without any very marked morphological changes. To illustrate the above remarks I will give the analyses by the methods to be described later, of (I) a very young brain, (2) an adult brain, (3) a brain from a case of dementia praecox, representing a pathological condition in which there is no visible morphological change, but an unmistakable chemical variation.

The preponderance in the water-soluble-non-colloidal constituents in the growing brain over the adult brain is quite apparent. There is also to be noticed in the adult brain a relative increase of lipoids, especially cerebrin, cholesterol, and lipoid sulphur, all colloidal constituents which go to the formation of the mertullated sheath, a morphological structure which plays an important rôle in the physiological differentiation of the cell.

The variation from the normal brain from dementia praecox is not nearly so striking, but nevertheless affects a group containing partially oxidized water-soluble sulphur compounds, the importance of which to the cell will be discussed more in detail in another paper.

[From the Huli Physiological Laboratory, University of Chicago, and the PATHOLOGICAL LABORATORY OF THE LONDON COUNTY ASYlums.]

\section{COLLECTION AND PRESERVATION OF MATERIAL. ${ }^{1}$}

By W, Kock aNd S. A. MaNy.

Received October I2, Igog.

Changes Likely to Occur in Material Before Chemical Samples Can Be Collected.-Whenever the circulation of the blood to a given tissue ceases or the tissue is removed from the body, the correlation of the different chemical reactions also ceases. Reactions of oxidation come to a stop and the hydrogen which was formerly depolarized by the oxygen with the formation of water now enters into reducing reactions. This is very well illustrated by Ehrlich's ${ }^{2}$ observations that certain tissues which do not reduce alizarin blue during life, do so after death by the addition of two hydrogen atoms. There must also be substances normally present in the tissues which can be reduced in similar ways. It is not necessary to assume the presence of special substances in the tissues which accelerate reactions of reduction as distinguished from oxidation, for the very reaction which is so important in oxidation is the one which after death is responsible for reduction. Not only can such new reactions be in-

1 For introduction see the preceding paper.

2Ehrlich, P., "Sauerstoff Bedurffniss des Organismus." 